\title{
EFEITO RESIDUAL DE SUPERFOSFATO, FOSFATO PRECIPITADO E FOSFORITA DE OLINDA EM CANA-DE-AÇUCAR *
}

\author{
Francisco de A. F. de Mello ** \\ Moacyr de O. C. do Brasil Sobrinho \\ S. JOLY \\ E. Malavolta $* * * *$
}

\section{RESUMO}

\begin{abstract}
Este trabalho apresenta os resultados de um estudo dos efeitos residuais de fertilizantes fosfatados realizado com auxilio de fósforo radioativo, do método de Neubauer e do método do $\Lambda$. niger.

Conclui-se, de um modo geral, que, dos adubos estudados, o menos solúvel, isto é, a Fosforita de Olinda é o que apresenta maior ação residual. O superfosfato e o Fertifos, um fosfato precipitado, praticamente não diferiram entre si.

Os resultados obtidos em laboratório estão de acordo com aqueles conseguidos sob condição de campo.
\end{abstract}

\section{INTRODUÇAO}

Existe, como se sabe, uma verdadeira escala de solubilidade entre os adubos fosfatados. Os mais solúveis são, em geral, indicados quando se pretende fornecer uma fonte fosfatada de pronta disponibilidade. Contrariamente, os menos solúveis são recomendados para fornecer fósforo lentamente ou para elevar o nível de fertilidade do solo no que respeita a esse elemento.

Embora geralmente se observe melhor resposta das plantas aos fosfatos solúveis (superfosfatos) no primeiro ano, o efeito residual de fosfatos insolúveis em água, tipo fosforita, é quase sempre maior do que os primeiros.

- Recebido para publicação em 23/9/1974.

Trabalho aprovado no IX Congresso Brasileiro de Ciência do Solo, Fortaleza, 1963.

* Departamento de Solo da ESALQ.

*** Instituto Zimotécnico da ESALQ.

**** Departamento de Química da ESALQ. 
Recentemente, verificou-se que a mistura superfosfato natural, tipo fosforita, tem boa propriedade fertilizante, seja esta medida em termos de solubilidade em água (VERDDE et al., 1960) seja ela avaliada em termos de colheita. Este último ângulo do problema foi estudado entre nós por COURY et al. (1960). Esses autores instalaram um ensaio em terreno arenoso (Regosol) em que testaram os efeitos do superfosfato simples, do Fertifos, um fosfato precipitado, e da Fosforita de Olinda, só ou misturada com superfosfato, em proporções variáveis, usando a cana-de-açúcar como planta teste. Verificaram que às duas misturas correspondiam as produções mais elevadas. $O$ cálculo da produção máxima revelou que a relação ideal entre os dois adubos era $1: 1$.

Neste trabalho são apresentados os resultados do estudo do efeito residual do super, Fertifos e da Fosforita de Olinda usados por COURY et. al. (1960).

\section{MATERIAL E MÉTODOS}

Como se mencionou, o trabalho de COURY et al. (1960) foi realizado em solo arenoso-Regosol. As características químicas desse solo se encontram no Quadro 1.

\begin{tabular}{ll}
\hline Características químicas do solo & Valor \\
\hline $\mathrm{pH}$ & 5,25 \\
Matéria orgânica \% & 0,491 \\
$\mathrm{~N} \%$ & 0,105 \\
e.mg $\mathrm{PO}_{4}{ }^{-3}$ solúvel em $\mathrm{H}_{2} \mathrm{SO}_{4} \quad 0,05 \mathrm{~N} / 100 \mathrm{~g}$ de terra & 0,201 \\
e.mg K${ }^{+}$trocável $/ 100 \mathrm{~g}$ de terra & \\
e.mg Ca++ trocável $/ 100 \mathrm{~g}$ de terra & 0,500 \\
\hline
\end{tabular}

Quadro I - Características químicas do solo do experimento de COURY et al. (1960).

O delineamento experimental empregado por COURY et al. (1960) foi o de blocos ao acaso, com 7 tratamentos repetidos 4 vezes.

1 - Testemunha (sem adubo)

$2-$ NK (sem fósforo)

$3-\mathrm{NK}+$ superfosfato

$4-\mathrm{NK}+$ Fertifos

$5-\mathrm{NK}+$ Fosforita de Olinda

$6-\mathrm{NK}+1 / 3$ de superfosfato $+2 / 3$ fosforita de Olinda 
$7-\mathrm{NK}+2 / 3$ de superfosfato $+1 / 3$ fosforita de Olinda

$\mathrm{O}$ fósforo foi aplicado na dose de $75 \mathrm{~kg}$ de $\mathrm{P}_{2} \mathrm{O}_{5}$ por hectare somente na ocasião do plantio.

Os canteiros tinham $90 \mathrm{~m}^{2}$ de superfície e a cana usada foi a $\mathrm{CB} 4176$.

Após a colheita da ressoca foram tomadas amostras compostas dos sul$\cos$ fertilizados dos tratamentos n. ${ }^{\text {os }} 2$ (NK), 3 (NK + superfosfato), 4 (NK + Fertifos) e 5 (NK + Fosforita de Olinda). Tais amostras serviram para a avaliação dos efeitos residuais dos fosfatos pelos processos seguintes:

a - Usando P32: Empregou-se a modificação de MENARD e MALAVOLTA (1962) para a determinação do valor «A» de FRIED e DEAN (1952), «L» de LARSEN (1952) ou «M» de BARBIER, LESAINT e TYSZKIEWICZ. O cálculo do fósforo residual disponível, entretanto, foi feito pela equação de LARSEN (1952) generalizada por MELLO (1963) para incluir o fósforo contido nas sementes.

b - Usando o método de Neubauer, citado por VANDECAVEYE (1948), empregando-se, porém, $50 \mathrm{~g}$ de terra por vaso.

c - Usando o método microbiológico do A. niger, de acordo com VANDECAVEYE (1948).

\section{RESULTADOS E DISCUSSÃO}

As produções da ressoca já foram apresentadas e discutidas por BRASIL SOBRINHO et al. (1962). Foram, em média, as seguintes, para os tratamentos considerados neste trabalho.

\section{Tratamento}

$\mathrm{NK}+$ Fosforita de Olinda

NK + Fertifos

$\mathrm{NK}+$ Superfosfato

NK, sem fósforo

\section{Produção - kg/parcela}

$1.105,7$

$1.073,0$

$1.075,0$

964,6

A determinação no laboratório do efeito residual dos tratamentos acima apresentou os seguintes resultados:

a - Usando P32

Os valores $\ll L \gg$ encontrados aparecem a seguir (Quadro II). 


\begin{tabular}{llllr}
\hline Tratamento & \multicolumn{4}{c}{ Valores «L» (mg P/100 g solo) } \\
\hline NK + Fosforita de Olinda & 6,05 & 6,83 & 8,52 & 11,49 \\
NK + Fertifos & 5,33 & 6,05 & 9,45 & 11,49 \\
NK + Superfosfato & 5,33 & 6,05 & 7,65 & 9,45 \\
NK, sem fósforo & 1,67 & 2,17 & 3,98 & 6,33 \\
\hline
\end{tabular}

Quadro II - Valores «L» obtidos nos diversos tratamentos.

A análise da variância dos valores «L» transformados em arc sen $\sqrt{\mathbf{x}}$ revelou diferenças entre os tratamentos, da ordem de 5\%. A aplicação do teste de Duncan (Quadro III) mostrou que os tratamentos que receberam fosfato não diferiram entre si, todos eles superando o tratamento NK, sem fósforo.

\section{b - Usando o método de Neubauer}

Com o emprego do método de Neubauer foram obtidos os seguintes resultados (Quadro IV).

A análise estatística dos valores do Quadro IV revelou diferença significativa entre tratamentos, da ordem de $5 \%$.

Os resultados fornecidos pelo teste de Duncan aparecem resumidos no Quadro V.

\begin{tabular}{lc}
\hline Tratamento & Valores arc sen $\sqrt{\mathrm{x}}$ médios \\
\hline $\mathrm{NK}+$ Fosforita de Olinda & 16,543 \\
$\mathrm{NK}+$ Fertifos & 16,325 \\
$\mathrm{NK}+$ Superfosfato & 15,385 \\
$\mathrm{NK}$, sem fósforo & 10,465
\end{tabular}

Limites de significância a 5\%: $D_{4}=3,723 ; D_{3}=3,647 ; D_{2}=3,494$

Quadro III - Valores «L» transformados em arc sen $\sqrt{x}$ e diferenças mí. nimas significativas pelo teste Duncan. 
Tratamento

NK, sem fósforo

$\mathrm{NK}+$ Superfosfato

$\mathrm{NK}+$ Fertifos

NK + Fosforita de Olinda mg de $P / 50$ g terra

\begin{tabular}{llll}
193 & 140 & 149 & 149 \\
257 & 359 & 257 & 483 \\
357 & 257 & 344 & 572 \\
507 & 249 & 741 & 572 \\
\hline
\end{tabular}

Quadro IV - mg de P disponivel por $50 \mathrm{~g}$ de terra, processo de Neubauer.

Tratamento

Média's

$\mathrm{NK}+$ Fosforita de Olinda

517,25

NK + Fertifos

382,50

$\mathrm{NK}+$ Superfosfato

339,00

NK, sem fósforo

Limites de significância a $5 \%: D_{4}=211,47 ; D_{3}=207,12 ; D_{2}=198,44$

Quadro V - mg de P disponível por $50 \mathrm{~g}$ de terra, processo de Neubauer, e limites de significância pelo teste de Duncan.

Verifica-se pelos dados do Quadro V que só os fosfatos menos solúveis, isto é, a Fosforita de Olinda e o Fertifos apresentaram efeito residual. Isso difere um pouco dos resultados colhidos com o emprego de fósforo radioativo. $\mathbf{E}$ que, naquele ensaio, também o tratamento NK + superfosfato superou o tratamento NK, sem fósforo. Deve-se notar, entretanto, que no caso presente, embora a diferença entre estes tratamentos não tenha sido significativa a 5\% pelo teste de Ducan ele esteve bem próximo do referido limite de significância.

\section{c- Usando o método do A. niger}

Os valores residuais dos fosfatos estudados pelo método do A. niger deram os seguintes resultados em pêso de micélio desenvolvido e em quantidade correspondente de $\mathrm{P}_{2} \mathrm{O}_{5}$. 


\begin{tabular}{lccccc}
\hline Tratamento & mg de micélio deduzido & & $\begin{array}{c}\text { mg de } \mathbf{P}_{2} \mathrm{O}_{5} \\
\text { o«Blank» }\end{array}$ & & (média) \\
\hline NK, sem fósforo & 17 & 25 & 17 & 19 & $\mathbf{0 , 0 1 3 0}$ \\
NK + superfosfato & 63 & 55 & 54 & 54 & 0,0530 \\
NK + Fertifos & 23 & 39 & 50 & 35 & $\mathbf{0 , 0 3 0 0}$ \\
NK + Fosforita de Olinda & 63 & 80 & 92 & 90 & $\mathbf{0 , 0 9 7 0}$ \\
\hline
\end{tabular}

Quadro VI - Peso de micélio de A. niger e quantidade correspondente de $\mathrm{P}_{2} \mathrm{O}_{5}$, em $\mathrm{mg} / \mathrm{g}$ de solo.

A análise de variância dos valores de pesos de micélio do Quadro VI revelou diferença significativa entre tratamentos. 0 teste de Duncan forneceu os resultados que aparecem no Quadro VII.

O exames dos dados do Quadro VII permite concluir:

a - $\mathrm{O}$ ef eito residual da Fosforita de Olinda foi maior que o dos demais tratamentos.

b - Os tratamentos superfosfato e Fertifos superaram a testemunha sendo que o primeiro superou o segundo.

Tratamento

Média

NK + Fosforita de Olinda

81,25

$\mathrm{NK}+$ Superfosfato

56,50

NK + Fertifos

36,75

$\mathrm{NK}$, sem fósforo

19,50

Limites de significância a $5 \%: D_{4}=15,20 ; D_{3}=14,92 ; D_{2}=14,19$

Quądro VII - Pesos médios de A. niger, em mg, e limites de significância pelo método de Duncan.

De um modo geral, observa-se que, dos adubos estudados a Fosforita de Olinda foi o que apresentou maior ef eito residual.

Pelo método de Neubauer o superfosfato teve efeito residual menor que o Fertifos, não sendo, mesmo, superior ao tratamento NK, sem fósforo; pelo método do A. niger, entretanto, o efeito residual do superfosfato foi superior ao do Fertifos, superando este último o tratamento NK, sem fósforo. Isso, de certa forma, significa que os efeitos residuais desses adubos se equivalem. Assim considerando, pode-se verificar que os resultados gerais 
obtidos em laboratório concordam bastante com aqueles conseguidos em condições de campo.

\section{SUMMARY}

\section{RESIDUAL EFFECTS OF PHOSPHATE FERTILIZERS}

The residual effects of phosphate fertilizers are studied by means of radioactive phosphorus and the Neubauer and A. niger methods.

The highest residual effect was observed for Olinda rockphosphate, the least soluble of those studied. Superphosphate and Fertifos, a pricipitated phosphate, were similar in their residual effects.

The laboratory results agree with those obtained under field conditions.

\section{LITERATURA CITADA}

BARBIER, G., M. LESAINT \& E. TYSZKIEWICZ 1954 - Recherches, au moyen d'isotopes, sur les phénomènes d'autodiffusion dans le sol et sur l'alimentation des plants. Ann. Agron. 5 : 923-959.

COURY, T., E. MALAVOLTA \& M. O. C. DO BRASIL SOBR 1960 - Ensaio do adubação em cana-de-açúcar, variedade $\mathrm{CB}$ 4176, com Fosforita de Olinda, em solo arenoso. Boletim n. ${ }^{9}$ 16, E. S. A. «Luiz de Queiroz», Piracicaba.

FRIED, M. \& L. A. DEAN 1952 - A concept concerning the measurement of available soil nutrients. Soil Sci. 73 : 263-272.

LARSEN, S. 1952 - The use of $\mathrm{P}^{32}$ in studies of the uptake of phosphorus by plants. Plant and Soil $4: 1-10$.

MENARD, L. N. \& E. MALAVOLTA 1962 - Estudos com adubos fosfatados marcados com fósforo - 32. $4^{\text {th }}$ Inter. Am. Symp. Peaceful Appl. Nucl. Energy 2 : 219-223, Cidade do México.

MELLO, F. A. F. 1963 - Generalizações das equações de Larsen, Fried e Dean e de Barbier, Lesaint e Tyszkiewicz para incluir as sementes como fonte de nutrientes disponíveis. Nota prévia apresentada ao 9.9 Congresso Brasileiro de Ciência do Solo, Fortaleza.

VANDECAVEYE, S. C. - 1948 - Biological methods of determining nutrients in soils. In Diagnastic Technique for Soils and Crops. Editado por H. B. Kitchen. The American Potash Institute Washington, pág. 199-230.

VERDADE, F. C., A. C. WUTKE \& A. Z. DO AMARAL 1960 - Estudo químico e granulométrico das misturas de Fosforita de Olinda e apatita do Araxá com superfosfato simples. Bragantia 19 (46) : 1041-1059. 
